\title{
Factors predicting change in corneal astigmatism following suture removal in post-penetrating keratoplasty patients
}

This article was published in the following Dove Press journal: Clinical Ophthalmology

\section{Vannarut Satitpitakul Nopphawan Uramphorn Ngamjit Kasetsuwan}

Department of Ophthalmology, Faculty of Medicine, Chulalongkorn University and King Chulalongkorn Memorial Hospital, Thai Red Cress Society, Bangkok, Thailand
Correspondence: Vannarut Satitpitakul Department of Ophthalmology, Faculty of Medicine, Chulalongkorn University and King Chulalongkorn Memorial Hospital,

Thai Red Cress Society, 1873 Rama 4 Road, Pathuwan, Bangkok 10330, Thailand

Tel +66 894959022

Fax +66 22528290

Email vannaruts@gmail.com
Purpose: To identify factors predicting corneal astigmatic change following suture removal in post-penetrating keratoplasty patients.

Patients and methods: This cross-sectional study included the data of 33 events of corneal suture removal from 27 post-penetrating keratoplasty patients. Sutures were removed from the steep axis of transplanted cornea with 16 interrupted corneal sutures. Corneal astigmatism was measured before and after suture removal using ORBSCAN II. Patients' demographic data and corneal biomechanics parameters obtaining from the Corvis ST were recorded. The changes in corneal astigmatism were calculated using vector analysis. The correlation between changes in corneal astigmatism and the potential factors was evaluated using Spearman's correlation coefficient and linear regression model.

Results: The mean corneal astigmatism before and after suture removal was $7.1 \pm 3.7$ diopters (D) and $5.5 \pm 3.2 \mathrm{D}$, respectively. The mean astigmatic change was $7.0 \pm 6.3 \mathrm{D}$ (range, $0.3-30.8 \mathrm{D}$ ) by vector analysis at $9.7 \pm 5.5$ weeks after suture removal. Change in corneal astigmatism was significantly correlated with pre-suture removal astigmatism (Rs $=0.47, P=0.01$ ). There was no correlation between the donor-recipient trephine diameter difference, the duration from corneal transplantation to suture removal, the number of removed sutures with the change in corneal astigmatism, and corneal biomechanics parameters $(P>0.05)$. Linear regression is given by the following equation: astigmatic change (D) $=1.05 \mathrm{x}$ pre-suture removal astigmatism $(\mathrm{D})-0.43$.

Conclusion: The astigmatic change after corneal suture removal in post-keratoplasty patients was significantly correlated with pre-suture removal astigmatism. These findings will permit a validated approach for reducing corneal astigmatism in post-keratoplasty patients.

Keywords: corneal astigmatism, corneal transplantation, keratoplasty, corneal biomechanics

\section{Introduction}

Corneal astigmatism is the leading cause of decreased visual acuity and impairs visual rehabilitation after penetrating keratoplasty. ${ }^{1,2}$ Suture removal is one of the crucial steps to control postoperative corneal astigmatism. However, the effect of suture removal is unpredictable, ranging from significant decrease to unexpected increase in astigmatism. ${ }^{3-5}$ Small number of studies had identified the factors influencing the change in corneal astigmatism. Previous studies showed that the keratometric values before suture removal, time of suture removal, the donorrecipient trephine diameter difference, and the indications of corneal transplantation were the potential factors. 4,5 
Corneal tissue displays biomechanical properties including elastic and viscoelastic properties, which are the capacity of an object to reversibly deform under the stress. ${ }^{6}$ Corvis ST (Oculus, Wetzlar, Germany), a noncontact tonometer using ultra-high-speed Scheimpflug technology, has been recently developed for corneal biomechanical properties assessment. ${ }^{7,8}$ In post-keratoplasty patients, corneal sutures provide stress to the transplanted cornea resulting in the change of corneal shape, thus change in corneal astigmatism after suture removal might be associated with the corneal biomechanics.

The purpose of this study was to identify the factors including corneal biomechanics properties that can predict corneal astigmatic change following corneal suture removal in post-keratoplasty patients.

\section{Materials and methods}

This prospective observational study included 27 patients who underwent corneal suture removal at Cornea Clinic, King Chulalongkorn Memorial Hospital, Bangkok, Thailand. The study was approved by the Institutional Review Board, Faculty of Medicine, Chulalongkorn University and was in adherence to the tenets of the Declaration of Helsinki. Written informed consent was obtained from either participant or legal guardian.

Participants who underwent penetrating keratoplasty with 16 interrupted corneal sutures for at least 6 months were evaluated for visual acuity and corneal astigmatism. The corneal astigmatism was obtained from central $3 \mathrm{~mm}$ zone using ORBSCAN II corneal topographer (Bausch \& Lomb, Orbtek Inc., Salt Lake City, UT). Participants with uncorrected visual acuity less than 20/40, corneal astigmatism at least 1.5 diopters, and planned to remove corneal suture in the steep axis for improving patients' visual acuity were enrolled. Exclusion criteria included corneal graft failure, active ocular infection, and unable to obtain corneal biomechanics by Corvis ST or keratometric measurement.

Corneal biomechanical properties were measured before suture removal with Corvis ST. The Covis ST parameters including the first applanation time (A1 time), maximal deformation amplitude (DA), and the radius at highest concavity (RHC) were recorded (Table 1). Age, gender, types and date of operation, indications of corneal transplantation and the donor-recipient trephine diameter difference, number of removed sutures, and time from keratoplasty to suture removal were also recorded.

Selective suture removal was done based on the axis of astigmatism. The number of removed sutures was decided according to attending physician. For each patient, topical antibiotic was prescribed for 1 week after suture removal. All participants were re-evaluated for corneal astigmatism after suture removal at the following visit.

\section{Statistical analysis}

Change in corneal astigmatism after suture removal was calculated using vector analysis based on magnitude and axis of astigmatism by Alpins method. ${ }^{9}$ Spearman's correlation test and linear regression model were used to evaluate the correlation between astigmatic change after suture removal and the following factors: donor-recipient trephine diameter difference, time of suture removal after transplantation, the number of removed sutures, corneal astigmatism before suture removal, and corneal biomechanics parameters including A1 time, DA, and RHC. $P$-value less than 0.05 was considered statistically significant. All analyses were performed using Stata Version 14.2 (College Station, TX, USA).

\section{Results}

The study included 33 data of corneal suture removal from 27 eyes of 27 post-penetrating keratoplasty participants. Fifteen participants $(51.9 \%)$ were female. The mean age of participants was $60.1 \pm 18.1$ years (range, $15-85$ years). Indications of corneal transplantation are shown in Table 2.

The mean corneal astigmatism was $7.1 \pm 3.7$ diopters (D) (range, 1.4-17.0D) before suture removal and 5.5 $\pm 3.2 \mathrm{D}$ (range, 0.1-14.1D) after suture removal. The decrease in corneal astigmatism after suture removal was 7.0 $\pm 6.3 \mathrm{D}$ (range, $0.3-30.8 \mathrm{D}$ ) by vector analysis. There was a significant correlation between corneal astigmatism

Table I Corneal biomechanics parameters acquired from Corvis ST

\begin{tabular}{|l|l|}
\hline Corneal biomechanics parameter & Definition \\
\hline $\begin{array}{l}\text { First applanation time (AI time) } \\
\text { Maximal deformation amplitude (DA) } \\
\text { Radius at highest concavity (RHC) }\end{array}$ & $\begin{array}{l}\text { Time from start until the first applanation (corneal flattening) in milliseconds } \\
\text { Deformation amplitude at the highest concavity in millimeters } \\
\text { Radius of corneal curvature at the highest concavity in millimeters }\end{array}$ \\
\hline
\end{tabular}


Table 2 Indications for corneal transplantation

\begin{tabular}{|l|l|}
\hline Indications for corneal transplantation & $\begin{array}{l}\text { Number of } \\
\text { patients (\%) (n=27) }\end{array}$ \\
\hline - Corneal dystrophy & $13(46.3)$ \\
- Graft failure & $5(17.9)$ \\
- Pseudophakic/aphakic bullous keratopathy & $5(17.9)$ \\
- Corneal scar & $3(10.7)$ \\
- Keratoconus & $\mathrm{I}(3.6)$ \\
- Corneal decompensation form secondary & $\mathrm{I}(3.6)$ \\
causes & \\
\hline
\end{tabular}

before suture removal and the change in corneal astigmatism (Rs=0.47, $P=0.01$ ). Mean follow-up time after suture removal was $9.7 \pm 5.5$ weeks (range, 4-25 weeks).

The donor trephine diameters were $0.25 \mathrm{~mm}$ larger than recipient trephine diameter in 3 eyes $(11.1 \%)$ and $0.50 \mathrm{~mm}$ larger than recipient diameter in 24 eyes $(88.9 \%)$. The mean duration from corneal transplantation to suture removal was $25.9 \pm 17.8$ months (range, 6-95 months) and the mean number of removed sutures was $1.6 \pm 0.7$ stitches (range, $1-3$ stitches). There was no correlation between donor-recipient trephine diameter differences, duration from corneal transplantation to suture removal, and number of removed sutures with change in corneal astigmatism ( $P=0.44,0.19$, and 0.97 , respectively)

The mean corneal biomechanics parameters including A1 time, DA, and RHC were 7.6 $51.3 \mathrm{~ms}$ (range, 6.5-12.8 $\mathrm{ms}$ ), $1.1 \pm 0.2 \mathrm{~mm}$ (range, $0.4-1.6 \mathrm{~mm}$ ), and $6.3 \pm 1.4 \mathrm{~mm}$ (range, 3.8-11.6 mm), respectively. There was no correlation between A1 time, DA, and RHC with the change in corneal astigmatism ( $P=0.55,0.84$, and 0.39 , respectively).

A simple linear regression was calculated to predict the change in corneal astigmatism after removing corneal sutures based on corneal astigmatism before removing sutures. A significant regression equation was found ( $\mathrm{F}$ $(1,31)=19.39, P=0.0001$ ), with an $\mathrm{R}^{2}$ of 0.38 (Figure 1). Change in corneal astigmatism after removing corneal sutures is equal to 1.05 (corneal astigmatism before removing suture) -0.43 . The change in corneal astigmatism increased 1.05D for each diopter of corneal astigmatism before removing sutures.

\section{Discussion}

According to our results, the corneal astigmatic change after suture removal was significantly correlated with pre-suture removal astigmatism. However, there was no correlation between change in astigmatism with time of

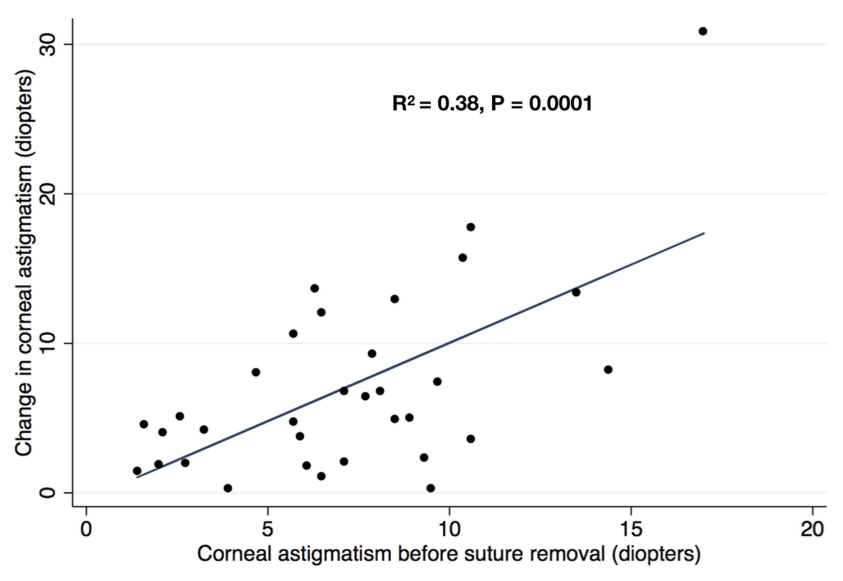

Figure I The correlation between corneal astigmatism before suture removal and change in corneal astigmatism after suture removal in post-keratoplasty patients.

suture removal when the sutures were removed between 6 and 95 months, the donor-recipient trephine diameter difference, the number of removed sutures, and the corneal biomechanics parameters including A1 time, DA, and RHC.

This study is unique in that we report the results of selective suture removal after keratoplasty with 16 interrupted corneal sutures. The technique of selective removal of corneal sutures on the axis of steepest keratometric value is the most popular technique used nowadays. We found that the higher level of astigmatism before suture removal results in the greater reduction in astigmatism. Our findings were consistent with previous studies, ${ }^{3-5}$ which studied in different suturing techniques such as eight interrupted sutures, single running, double running, and combined interrupted and running suture. However, all sutures were removed at the same time in previous studies and led to the conclusion of unpredictable change in corneal astigmatism after suture removal. ${ }^{4,5}$ Based on the regression equation we analyzed in this study, the change in corneal astigmatism increased 1.05D for each diopter of corneal astigmatism before suture removal. These findings can be used to predict the amount of corneal astigmatic change following suture removal in post-keratoplasty patients. These findings help decreasing unnecessary suture removal, which might lead to vision-threatening complications such as graft rejection, retained suture material, infection, wound dehiscence, and even induced astigmatism. ${ }^{10-12}$ In addition, the more predictable method to adjust corneal astigmatism reduces hospital costs and visits.

On the basis of our findings, there is no correlation between astigmatic change and time of suture removal (6- 
95 months). Our finding was in agreement with the previous studies using vector analysis to calculate the astigmatic change that demonstrated no correlation between astigmatic change and time of suture removal when the sutures were removed 5-72 months after penetrating keratoplasty. $^{4,5}$ Unpredictable change of astigmatism based on time of suture removal is due to several factors affecting corneal wound healing such as recipient age, indications for keratoplasty, and post-operative medications. ${ }^{13}$ We suggest not removing suture until the corneal wound is adequately healed to avoid wound leakage and subsequent infection following suture removal. Moreover, once acceptable astigmatism is achieved after suture removal. Sutures should be left in place to avoid undesirable astigmatic change at least 95 months after keratoplasty, excepting any suture complication.

The donor-recipient trephine diameter difference was previously demonstrated to be the factor influencing astigmatic change following suture removal. ${ }^{5}$ This parameter, however, did not show any significant difference in term of astigmatic change after suture removal in our study. This result might be due to the discrepancy between donor graft size and recipient trephined size was rather constant in our study.

Our analyses revealed that change in astigmatism after suture removal is independent of the number of removed sutures. Similar results of astigmatic change were obtained when 1-4 sutures were removed at one visit. Likewise, Burk et al found that following suture removal, 2-3 diopters of astigmatic change could be expected regardless of the number of removed sutures, ranging from 1 to 4 sutures. ${ }^{14}$ Mean follow-up time after suture removal varied greatly among participants in our study. However, it was not appeared to affect the astigmatic change. Burk et al similarly found that after 10 weeks of corneal transplantation, removal of a single interrupted suture in each followup visit resulted in similar astigmatic change regardless of follow-up time. ${ }^{14}$

Corneal biomechanics are novel parameters reflecting viscoelastic properties of cornea. Corvis ST monitors corneal deformation using an ultra-high-speed Scheimpflug camera with UV-free $455 \mathrm{~nm}$ light and provides a set of corneal deformation parameters. Previous studies evaluating corneal biomechanics in post-keratoplasty eyes showed that the deformation amplitude (DA) of transplanted cornea was significantly higher than normal eyes, while the radius at the highest concavity (RHC) was significantly smaller than normal eyes. ${ }^{15,16}$ This might suggest that corneal transplantation tended to weaken the corneal integrity. To the best of our knowledge, the study determining the effect of corneal biomechanics on the astigmatic change after suture removal has not been reported yet. Our study included the three most representative and repeatable corneal biomechanics parameters acquired from Corvis ST, which are A1 time, DA, and RHC. ${ }^{7,15-17}$ This study found no significant difference in astigmatic change among eyes with different corneal biomechanics. We hypothesized that corneal grafts might reach their maximal tensile strength when suture removal was initiated, so we could not find the significant relationship between these 2 factors. Corneal biomechanics probably have no role in the prediction of astigmatic change after removal, yet these parameters could have potential benefits for monitoring postoperative wound healing. Repeatable and stable corneal biomechanics values in the follow-up period after keratoplasty may serve as the indicators for completely healed corneal grafts and suture removal can be safely carried out. To our knowledge, this is the first study to evaluate this relationship.

Limitation of this study is the relatively small sample size. Further large-scale studies are needed especially for more accurate equation of astigmatic change after suture removal.

\section{Conclusion}

The astigmatic change after corneal suture removal in post-keratoplasty patients was significantly correlated with pre-suture removal astigmatism. These findings will permit a validated approach for reducing corneal astigmatism in post-keratoplasty patients.

\section{Acknowledgments}

This research has been supported by the Rachadaphiseksomphot Endowment Fund of Chulalongkorn University. The abstract of this paper was presented at the 32nd AsiaPacific Academy of Ophthalmology Congress as a poster presentation.

\section{Disclosure}

The authors report no conflicts of interest in this work.

\section{References}

1. Van Meter WS, Gussler JR, Soloman KD, Wood TO. Postkeratoplasty astigmatism control. Single continuous suture adjustment versus selective interrupted suture removal. Ophthalmology. 1991;98:177-183. 
2. Acar BT, Vural ET, Acar S. Does the type of suturing technique used affect astigmatism after deep anterior lamellar keratoplasty in keratoconus patients? Clin Ophthalmol. 2011;5:425-428. doi:10.2147/ OPTH.S18889

3. Binder PS. The effect of suture removal on postkeratoplasty astigmatism. Am J Ophthalmol. 1988;105:637-645. doi:10.1016/00029394(88)90057-8

4. Mader TH, Yuan R, Lynn MJ, Stulting RD, Wilson LA, Waring GO. Changes in keratometric astigmatism after suture removal more than one year after penetrating keratoplasty. Ophthalmology. 1993;100:119-127. doi:10.1016/s0161-6420(93)31 705-7

5. Yilmaz S, Ali Ozdil M, Maden A. Factors affecting changes in astigmatism before and after suture removal following penetrating keratoplasty. Eur J Ophthalmol. 2007;17(3):301-306.

6. Soergel F, Jean B, Seiler T, et al. Dynamic mechanical spectroscopy of the cornea for measurement of its viscoelastic properties in vitro. Ger J Ophthalmol. 1995;4:151-156.

7. Rio-Cristobal A, Martin R. Corneal assessment technologies: current status. Surv Ophthalmol. 2014;59:599-614. doi:10.1016/j.survophthal. 2014.05.001

8. Pinero DP, Alcon N. In vivo characterization of corneal biomechanics. J Cataract Refract Surg. 2014;40:870-887. doi:10.1016/j. jcrs.2014.03.021

9. Alpins NA. A new method of analyzing vectors for changes in astigmatism. J Cataract Refract Surg. 1993;19:524-533.
10. Christo CG, van Rooij J, Geerards AJ, Remeijer L, Beekhuis WH. Suture-related complications following keratoplasty: a 5-year retrospective study. Cornea. 2001;20:816-819.

11. Fujii S, Matsumoto Y, Fukui M, et al. Clinical backgrounds of postoperative keratoplasty patients with spontaneous wound dehiscence or gaps after suture removal. Cornea. 2014;33:1320-1323.

12. Padrón-Pérez N, Filloy A, Martí-Huguet T. Complete dehiscence of a DALK graft after early suture removal. Eye. 2014;28:909-911. doi:10.1038/eye.2014.59

13. Melles GR, Binder PS. A comparison of wound healing in sutured and unsutured corneal wounds. Arch Ophthalmol. 1990;108:14601469. doi:10.1001/archopht.1990.01070120108039

14. Burk LL, Waring GO 3rd, Radjee B, Stulting RD. The effect of selective suture removal on astigmatism following penetrating keratoplasty. Ophthalmic Surg. 1988;19:849-854.

15. Maeda N, Ueki R, Fuchihata M, Fujimoto H, Koh S, Nishida K. Corneal biomechanical properties in 3 corneal transplantation techniques with a dynamic Scheimpflug analyzer. Jpn J Ophthalmol. 2014;58:483-489. doi:10.1007/s10384-014-0344-2

16. Modis L Jr, Hassan Z, Szalai E, Flaskó Z, Berta A, Nemeth G. Ocular biomechanical measurements on post-keratoplasty corneas using a Scheimpflug-based noncontact device. Int $J$ Ophthalmol. 2016;9:235-238. doi:10.18240/ijo.2016.02.09

17. Hon Y, Lam AK. Corneal deformation measurement using Scheimpflug noncontact tonometry. Optom Vis Sci. 2013;90(1):e1e8. doi:10.1097/OPX.0b013e31828e92eb
Clinical Ophthalmology

\section{Publish your work in this journal}

Clinical Ophthalmology is an international, peer-reviewed journal covering all subspecialties within ophthalmology. Key topics include: Optometry; Visual science; Pharmacology and drug therapy in eye diseases; Basic Sciences; Primary and Secondary eye care; Patient Safety and Quality of Care Improvements. This journal is indexed on PubMed
Dovepress

Central and CAS, and is the official journal of The Society of Clinical Ophthalmology (SCO). The manuscript management system is completely online and includes a very quick and fair peer-review system, which is all easy to use. Visit http://www.dovepress.com/ testimonials.php to read real quotes from published authors. 